\title{
Expanded Thermodynamic Model for Microbial True Yield Prediction
}

\author{
Jinghua Xiao, Jeanne M. VanBriesen \\ Department of Civil and Environmental Engineering, Carnegie Mellon University, \\ Pittsburgh, Pennsylvania 15213-3890; telephone: (412)268-4603; fax: (412)268-7813; \\ e-mail: jeanne@cmu.edu
}

Received 31 January 2005; accepted 13 July 2005

Published online 9 September 2005 in Wiley InterScience (www.interscience.wiley.com). DOI: 10.1002/bit.20700

\begin{abstract}
Thermodynamic methods to predict true yield and stoichiometry of bacterial reactions have been widely used in biotechnology and environmental engineering. However, yield predictions are often inaccurate for certain simple organic compounds. This work evaluates an existing method and identifies the cause of prediction errors for compounds with low degree of reductance of carbon. For these compounds, carbon, not energy or reducing equivalents, constrains growth. Existing thermodynamically-based models do not account for the potential of carbon-limited growth. The improved method described here consists of four balances: carbon balance, nitrogen balance, electron balance, and energy balance. Two efficiency terms, $K 1$ and $K 2$ are defined and estimated from a priori analysis. The results show that $K 1$ and $K 2$ are nearly the same in value so that only one coefficient, $K=0.41$ is used in the modified model. Comparisons with observed yields show that use of the new model and parameters results in significantly improved yield estimation based on inclusion of the carbon balance. The average estimation error is less than $6 \%$ for the data set presented.

(C) 2005 Wiley Periodicals, Inc.
\end{abstract}

Keywords: bacterial yield; carbon balance; energetics; stoichiometry; thermodynamic model

\section{INTRODUCTION}

In order to understand the behavior of microorganisms in the environment, predict the biodegradation of anthropogenic compounds, or develop stoichiometries for biochemical processes, a critical parameter is the bacterial yield, representing the amount of biomass that can be formed for a unit of substrate consumed. Prediction of bacterial yield has been the focus of numerous studies (Heijnen and Roels, 1981; McCarty, 1965; Roels, 1980; Roels, 1983). The method of McCarty (McCarty, 1965, 1969, 1971, 1972a,b, 1975; Rittmann and McCarty, 2001) has been widely used in environmental engineering (see for example: Alvarez et al., 1994; Arcangeli and Arvin, 1999; Beller et al., 1996; Burland and Edwards, 1999; Corseuil and Weber, 1994; Edwards and Grbic-Galic, 1994; Hayes et al., 1998; Hooker et al., 1994;

Correspondence to: J.M. VanBriesen

Contract grant sponsor: National Science Foundation

Contract grant number: BES-0219330
Muller et al., 2003; Noguera et al., 1988; Nowak et al., 1999; Schill et al., 1999; Woo and Rittmann, 2000; Zitomer, 1998). This method was expanded by VanBriesen and Rittmann (2000) to predict step-wise yields for multi-step biodegradation reactions. VanBriesen (2001) and Yuan and VanBriesen (2002) provided additional modifications by considering oxygenase reactions. These modifications improved estimates of bacterial yield on specific anthropogenic compounds, such as chelating agents (e.g., EDTA, NTA). VanBriesen (2002) further compared the method with the dissipation energy based method of Heijnen et al. (1992), and found the methods to be mathematically consistent and to have similar prediction errors. However, despite the increasing complexity added to the model to improve predictions in systems with complex organic substrates, this model continued to show poor predictive ability for some simple substrates. For example, the estimated yield on glyoxylate, an intermediate formed during the biodegradation of EDTA and NTA, was over predicted with an error of $+88 \%$ (Yuan, 2004).

The foundation of the present work is the hypothesis that yield prediction errors in thermodynamic models are due to the assumption that electron and energy balance are sufficient to constrain growth predictions. This work demonstrates explicit inclusion of carbon balance enables thermodynamic yield prediction models to account for the potential for carbon-limited growth, thus improving yield prediction for compounds containing highly reduced carbon. Based on the requirements for "black box" yield prediction models suggested by Heijnen et al. (1992), an expanded thermodynamic yield prediction methodology following on the seminal work of McCarty $(1965,1972 b)$ is presented.

\section{Fundamentals of Thermodynamic Yield Prediction}

The fundamental premise of the original thermodynamic model was that electron and energy balances are coupled in microorganisms, and this linkage can be exploited to estimate the yield based on bacterial energetics. The electron flow and energy consumption can be illustrated as in Figure 1. In all the 

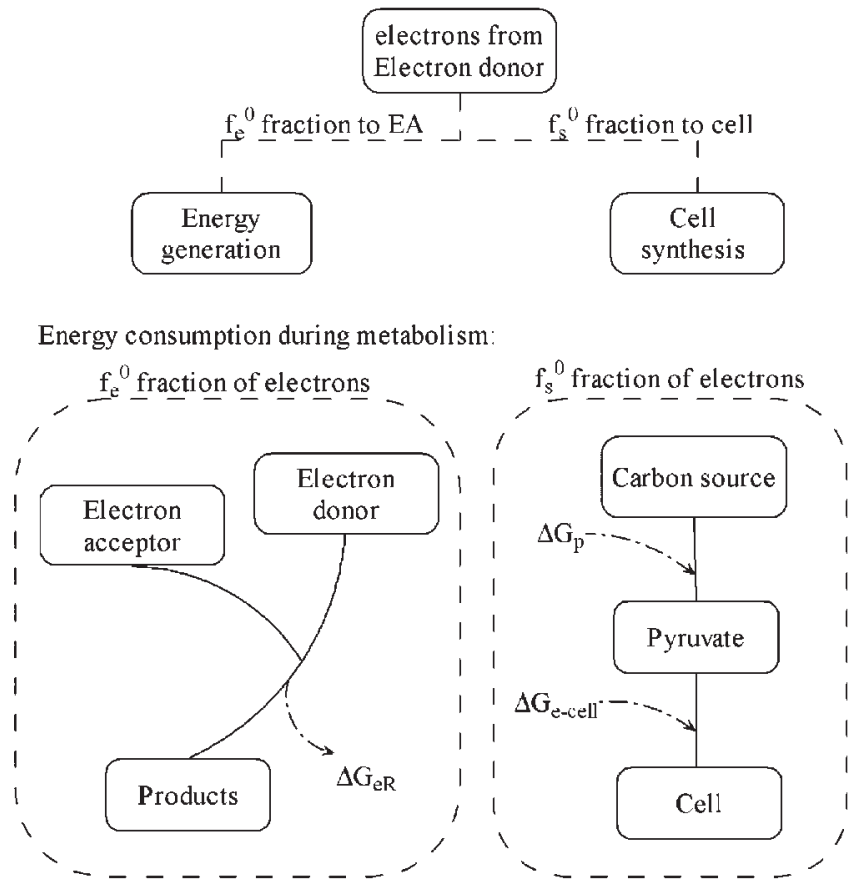

Figure 1. Schematic of electron and energy flow in the original thermodynamic model.

schematic figures in this paper, a solid line (_- ) is used to represent mass flow, dashed line ( - - - ) to represent electron flow and a dotted dashed line $(-\cdot-\cdot)$ to represent energy flow. The original formulation described a fraction of electrons $\left(f_{\mathrm{e}}^{0}\right)$ from the electron donor (ED) substrate that is transferred to the electron acceptor (EA) substrate for energy generation and a fraction of electrons $\left(f_{\mathrm{S}}^{0}\right)$ from the electron donor substrate that is utilized by the microorganisms for cell synthesis as shown at the top of Figure 1. Carbon balance was not explicitly considered in the model. However, when the electron donor and carbon source are the same compound, electrons and carbon were assumed to move in tandem with carbon dioxide produced in the energy generating reaction (representing carbon in its most oxidized form and thus having no additional energy value) and cell carbon produced in the anabolic reaction.

Energy is produced from the flow of electrons from donor to acceptor (bottom left of Fig. 1). The assumed efficiency of capture of the energy available from the ED/EA couple is termed $K$, where $K$ is considered in the range of $0.2-0.8$ (McCarty, 1969). Evaluation of experimental yield data suggested a best fit $K$ of $0.2-0.3$ for aerobic heterotrophs and 0.4-0.7 for anaerobic heterotrophs (McCarty, 1971; VanBriesen, 2002). But $K$ is often assumed to take the value of 0.6 as this has been predictive of yields in wastewater treatment applications (Rittmann and McCarty, 2001). The captured energy is used in the process of cell synthesis from substrate to cell through a theoretical intermediate, pyruvate (bottom right of Fig. 1).

The coupling of electron and energy balances follows from the concept that organisms maximize yield by balancing the flow of electrons between anabolic and catabolic processes. The electron balance requires that the electrons stored in the carbon of the formed biomass and the electrons shuttled to the electron-donor substrate for energy generation must sum to the electrons originally available from the electron-donor substrate $\left(f_{\mathrm{e}}^{0}+f_{\mathrm{s}}^{0}=1\right)$. Energy balance requires that the energy generated by the electron donor-electron acceptor reaction is equal to the energy utilized in cell synthesis plus the energy dissipated as heat. When the efficiency of energy capture is termed $K$, the energy balance can be expressed as $K\left(f_{e}^{0} \Delta G_{\mathrm{eR}}\right)=f_{s}^{0} \Delta G_{\mathrm{e}-\mathrm{s}}$. The released energy, $\Delta G_{\mathrm{eR}}$, is the sum of the energy released from the oxidation half reaction of $\mathrm{ED}\left(\mathrm{R}_{\mathrm{ED}}\right)$ and the reduction half reaction of $\mathrm{EA}\left(\mathrm{R}_{\mathrm{EA}}\right)$ in $\mathrm{kJ}$ per electron equivalent. The energy consumed during cell synthesis $\left(\Delta G_{\mathrm{e}-\mathrm{s}}\right)$ is calculated as the sum of the energy consumed to transform the carbon source to pyruvate, $\Delta G_{\mathrm{p}}$, the energy consumed to transform the nitrogen source to $\mathrm{NH}_{4}^{+}, \Delta G_{\mathrm{n}}$, and the energy consumed to transform common cell intermediates (assumed to be at the energy level of pyruvate and ammonia) to cell biomass, $\Delta G_{\mathrm{e} \text {-cell. }}$. It is also calculated in units of $\mathrm{kJ}$ per electron equivalent. This is represented as $\Delta G_{\mathrm{e}-\mathrm{s}}=\frac{\Delta G_{\mathrm{p}}}{K^{\mathrm{m}}}+\Delta G_{\mathrm{e}-\text { cell }}+\frac{\Delta G_{\mathrm{n}}}{K}$.

Finally, the bacterial theoretical maximum or true yield in units of electron fraction, $f_{\mathrm{S}}^{0}$, can be estimated by solving the electron balance and the energy balance simultaneously. Once the fraction of electrons from the electron donor that can be sent to synthesis is known, the maximum yield in carbon mole unit, $Y_{\mathrm{m}}$, is defined since the electrons going to cell synthesis and the reductance degree of carbon in the biomass are known. It can be calculated from the ratio of electrons flowing to synthesis $\left(f_{\mathrm{s}}^{0} \times \gamma_{\mathrm{s}}\right)$ to the reductance degree of carbon in cells $\left(\gamma_{\mathrm{X}}\right)$. Here, the reductance degree refers to the ability to donate electrons when a certain element is oxidized to its highest valence. For example, the reductance degree of carbon in methane (with valence of -4 ) is 8 and the reductance degree of carbon in carbon dioxide (with valence of +4 ) is zero. Thus, the maximum bacterial yield $\left(Y_{\mathrm{m}}\right)$ in the unit of mole-C cells/mol-C substrate is $Y_{\mathrm{m}}=f_{\mathrm{s}}^{0} \frac{\gamma_{\mathrm{s}}}{\gamma_{\mathrm{X}}}$

\section{Problems with Thermodynamic Yield Predictions}

Although the original thermodynamic model worked well for many systems, it was not predictive for all cases. Compounds that were highly reduced (e.g., $\mathrm{CH}_{4}, \gamma_{\mathrm{s}}=8$ ) or highly oxidized (e.g., glyoxylate, $\gamma_{\mathrm{s}}=2$ ) often showed significant prediction errors. (VanBriesen, 2001, 2002) Initially, researchers proposed electrons or energy that was not accounted for in the model as reasons for the poor predictive ability the model showed in certain systems. For example, Woo and Rittmann (2000) initially identified the oxygenasecatalyzed reactions in polycyclic aromatic hydrocarbons (PAHs) biodegradation as an additional sink for electrons that should be considered in the model. VanBriesen (2001) and Yuan and VanBriesen (2002) expanded on this concept and modified the electron and the energy balances to account for 
the investments necessary to perform oxygenase reactions. VanBriesen (2001) further hypothesized that the efficiency of energy capture might not be constant but might depend upon the type of organism or its environment. Extensive testing of the original model and the modifications was (and is) hampered by the variability in experimental conditions for yield measurements reported in the literature. The modifications to the model improved predictions for some specific compounds, and poor predictive ability in some cases could challenge experimental results rather than invalidating the model. However, the poor predictive ability the model showed for some simple substrates where the biotransformation pathways involved no specialized enzymes and the experimental yields were well verified was still unexplained.

\section{Considering Carbon Balance}

The original thermodynamic model does not specifically track carbon flow through a mass balance but rather considers that carbon balance will follow electron balance since the ED substrate is often the carbon-source (CS) substrate. Our re-analysis of the structure of the original model indicates that this assumption directly affects the model's predictive ability and leads to considerable estimation error for some substrates. For example, we consider the case of methanotrophs, organisms that utilize methane as electron donor and carbon source and utilize oxygen as a terminal electron acceptor. Many researchers have evaluated this system and the observed yield for this type of growth is $0.55 \mathrm{C}$-mole cells/ C-mole substrate.(Linton and Stephenson, 1978; Heijnen and Roels, 1981) However, yield prediction with the classic thermodynamic model indicates a yield of 1.07 $\mathrm{C}$-mole cells/C-mole substrate when the energy capture efficiency is assumed to be 0.6. VanBriesen (2001) utilizes a modification that accounts for the diversion of electrons and energy for the initial oxygenation step and suggests an energy efficiency of 0.4 is more likely for this aerobic heterotroph. These two changes improve the yield prediction significantly. However, the fact that the initial implementation of the model resulted in a carbon-based yield above 1 was suggestive of a problem with a constraint in the model formation. Figure 2 shows yield predictions with the original thermodynamic model and the model modified for oxygenase energy diversion (following VanBriesen, 2001). Yield predictions for all possible energy capture efficiencies from 0 to 1 are shown. Horizontal lines are used to show the observed yield of $0.55 \mathrm{C}$-moles cells/C-mole substrate and the theoretical maximum yield of $1.0 \mathrm{C}$-moles cells/ C-mole substrate. While accounting for energy and electron diversion in oxygenase reactions and adjusting the assumed energy efficiency to 0.4 improves the predictive ability of the original model, the fact that at high assumed energy efficiency the model would predict more than 1 mole of carbon to cells from each mole in the original carbon source substrate suggests that the model is unconstrained on carbon balance. Utilizing the original unamended prediction of yield (1.07 C-mole/ $\mathrm{C}$-mole) will result in writing a balanced stoichiometry that

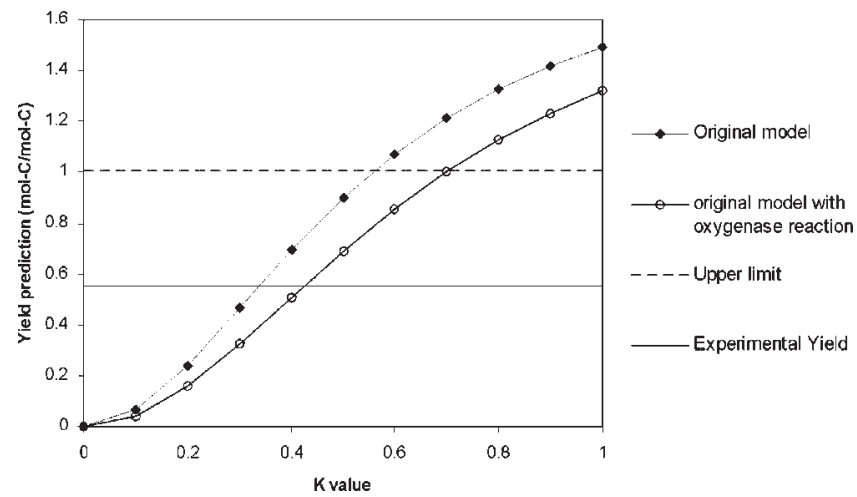

Figure 2. Yield prediction for methane for different assumed energy capture efficiencies based on the original model and the model modified for diversion of electrons and energy for oxygenase reactions. The upper limit of 1 mole of carbon in cells per mole of carbon from carbon-source substrate is shown as a dashed horizontal line. The observed experimental yield is shown as a solid horizontal line.

implies the organisms are fixing inorganic carbon in addition to utilizing carbon from methane for cell growth. This is extremely unlikely.

\section{Considering Carbon and Electron Flow}

The available electrons from an organic electron donor depend upon the valence change of the carbon from that compound to its degradation products. For example, when organisms use glyoxylate as a carbon-source electron-donor substrate, electrons must flow to the electron acceptor for energy generation but also to anabolic processes in order to take the carbon from a degree of reductance of 2 (in glyoxylate) to 4.2 for biomass. These electrons must be diverted from the catabolic pathway, reducing the fraction of electrons available for energy generation $\left(f_{\mathrm{e}}^{0}\right)$ and increasing the fraction of electrons to synthesis $\left(f_{\mathrm{S}}^{0}\right)$. This upsets the balance assumed in the original thermodynamic model. The allocation of electrons from electron donor to the two uses is not controlled solely by energy capture efficiency and the relative energies of the catabolic and anabolic processes. In addition, considering a highly reduced substrate such as methane, which contains more reducing equivalents per carbon than are needed for carbon incorporation into cells, only $Y_{\mathrm{m}} \times \gamma_{\mathrm{X}}$ mole electrons will go into cell mass with the carbon if $Y_{\mathrm{m}}$ fraction of the available carbon is incorporated into biomass. The other electrons are shuttled to the electron acceptor and generate energy even if this energy cannot be used by the organisms. The relationship between electron flow and carbon flow is shown schematically in Figure 3. Carbon flow is represented as solid lines and electron flow is represented as dashed lines. For a highly reduced substrate like methane (on the left), electron and carbon flow are uncoupled with excess electrons shuttled to the electron acceptor. For a highly oxidized substrate like glyoxylate (on the right), electron and carbon flow are uncoupled with electrons diverted from energy generation into synthesis reactions. For microorganisms, the catabolic processes and 

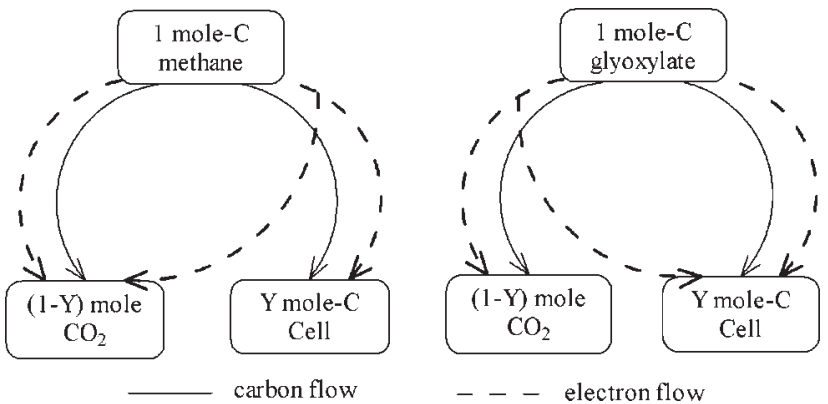

Figure 3. The relationship between carbon flow and electron flow for heterotrophs. Carbon flow is shown as a solid line and electron flow is shown as a dashed line. For highly reduced substrate like methane, electrons will divert from the carbon incorporated into new cell; but for highly oxidized substrate like glyoxylate, extra electrons have to be invested for reducing the carbon from lower reductance degree to the reductance degree of cell carbon.

the anabolic processes achieve a balance based on the supply and demand of energy, reducing equivalents, and macronutrients ( $\mathrm{C}$ and $\mathrm{N}$ predominately). The observed true biomass yield on a given substrate is the result of this balance. So carbon flow and electron flow during substrate degradation are two separate processes even when the carbon source and electron donor are the same substrate. Moreover, when carbon is the only electron donor in a heterotrophic system, carbon flow can control the flow of electrons to catabolic and anabolic processes, effectively bypassing the electron and energy balance structure of the original thermodynamic model. Thus, incorporation of a carbon balance in the thermodynamic yield prediction model is critical.

\section{Evaluating the Effect of Carbon Source Degree of Reductance on Yield Prediction}

As shown in Figure 3, the degree of reductance of the carbon source affects whether excess electrons are sent to the electron acceptor and energy dissipation increases or whether additional electrons are needed in synthesis thus reducing those available for energy generation. Since the original model estimates bacterial yield directly from the coupled energy and electron balance without consideration of the effect of carbon reductance degree on yield prediction, we expect yield predictions would be more accurate when the two flows are nearly balanced. This occurs when the degree of reductance of the substrate is the same as the biomass to be formed. In that case, no shifting of electrons from the paths dictated by energy and electron balance is needed. Since the carbon unit yield, $Y_{\mathrm{m}}$, is related to the electron unit yield, $f_{\mathrm{S}}^{0}$ through $Y_{\mathrm{m}}=f_{\mathrm{s}}^{0} \frac{\gamma_{\mathrm{s}}}{\gamma_{\mathrm{x}}}$, we see that the two yield values, although in different units, will have the same numerical value $\left(Y_{\mathrm{m}}=f_{\mathrm{s}}^{0}\right)$ when $\gamma_{\mathrm{S}}=\gamma_{\mathrm{X}}$. When the reductance degree of substrate is far from $\gamma_{X}$, the difference between the electron fraction and the carbon fraction can create serious problems in predicted yields. Here, $\gamma_{X}$ is assumed to be 4.2 according to the assumed formula for biomass of $\mathrm{CH}_{2} \mathrm{O}_{0.6} \mathrm{~N}_{0.2}$ (VanBriesen and Rittmann, 2000). Thus, the original yield prediction model utilizing only electron and energy balance is expected to show larger estimation errors for substrates with much higher or lower reductance degree than 4.2. In order to verify this supposition, substrates for which the bacterial yields have been measured experimentally were considered. Because oxygenase reactions are known to affect yield (VanBriesen, 2001; Yuan and VanBriesen, 2002) only degradation processes without these reactions are considered. The experimental yield and the estimated yield following the original thermodynamic model for 20 substrates are listed in Table I; predictions with the commonly used $K=0.6$ and predictions with $K=0.41$ are shown. The relationship between the estimation error and $\gamma_{s}$ is shown in Figure 4. From Figure 4, we can see the tendency of the estimation error clearly: the estimation error decreases with the increase of $\gamma_{\mathrm{s}}$ when $\gamma_{\mathrm{s}}$ is less than 4.2 and the error increases with the increase of $\gamma_{\mathrm{s}}$ when $\gamma_{\mathrm{s}}$ is greater than 4.2. The model is most accurate for prediction when $\gamma_{\mathrm{s}}$ is close to 4.2, regardless of the assumed energy efficiency. Thus, as expected from the analysis of the use of carbon fraction and electron fraction in the original model, higher errors are seen when substrates are more or less reduced than cells.

The cause of the yield prediction error discussed above is clearly related to the assumption that carbon flow will follow electron flow. While this simplified the original model formulation and was generally acceptable when working with carbon sources that were at the typical oxidation state of zero $(\gamma=4)$, for substrates that are highly reduced or highly oxidized, the assumption was not valid. For heterotrophs electrons (or reducing equivalents) are carried into the system with the carbon and the carbon flow can control the transfer of those electrons into catabolic and anabolic processes.

\section{Considering Nitrogen Source}

Organisms also require nitrogen sources, and bacterial yield varies with the redox state of the available nitrogen source with higher yields seen for growth on nitrogen as ammonia and reduced yields seen for growth on more oxidized forms. Different $\mathrm{N}$-sources affect not only the energy balance but also the electron flow because they are electron sinks and have different requirements for electrons during the reduction of nitrogen. Often, the nitrogen source is $\mathrm{NH}_{4}^{+}$where $\mathrm{N}$ has the valence of -3 and reductance degree of 8 . No electron inputs are needed to this $\mathrm{N}$-source as it is already at the valence state of cell nitrogen. But when bacteria use $\mathrm{NO}_{3}^{-}$or other nitrogen source to incorporate into new biomass, electrons are invested for the reduction of this nitrogen. For example, when nitrate $\left(\mathrm{NO}_{3}^{-}\right)$acts as $\mathrm{N}$-source, 8 electrons are needed to change $1 \mathrm{~mol} \mathrm{~N}$ from $\mathrm{N}(+5)$ to $\mathrm{N}(-3)$. Therefore, when the nitrogen source is not ammonia, electron flow to the terminal electron acceptor is reduced. Also, electron transfers to the nitrogen source may release or consume energy and this must be considered in the overall energy balance.

The original thermodyanamic model had only two flows for electrons - to the EA or to cell synthesis. In order to 
Table I. Estimated yields using the original model ( $\mathrm{pH}$ is assumed as 7).

\begin{tabular}{|c|c|c|c|c|c|c|c|}
\hline Substrates & $\gamma_{\mathrm{s}}$ & $\begin{array}{r}Y_{\text {Exp }}(\text { mol-C cell/ } \\
\text { mol-C substrate })\end{array}$ & $\begin{array}{l}\text { Reference for } \\
Y_{\text {Exp }}\end{array}$ & $\begin{array}{c}Y_{\text {Est }}(\text { mol-C cell/ } \\
\text { mol-C substrate }) \\
K=0.6\end{array}$ & $\begin{array}{c}\text { Error } \\
(K=0.6)\end{array}$ & $\begin{array}{c}Y_{\text {Est }}(\text { mol-C cell/ } \\
\text { mol-C substrate }) \\
K=0.41\end{array}$ & $\begin{array}{c}\text { Error } \\
(K=0.41)\end{array}$ \\
\hline Oxalate & 1 & 0.086 & [4] & 0.185 & $114.75 \%$ & 0.134 & $55.27 \%$ \\
\hline Formate & 2 & 0.162 & [4] & 0.333 & $105.46 \%$ & 0.241 & $48.55 \%$ \\
\hline Glyoxylate & 2 & 0.220 & [1] & 0.354 & $61.03 \%$ & 0.256 & $16.43 \%$ \\
\hline Tartrate & 2.5 & 0.280 & {$[1]$} & 0.417 & $48.78 \%$ & 0.301 & $7.57 \%$ \\
\hline Malonate & 2.67 & 0.238 & {$[1]$} & 0.396 & $66.20 \%$ & 0.277 & $16.19 \%$ \\
\hline Iminodiacetate & 3 & 0.333 & [2] & 0.469 & $40.84 \%$ & 0.337 & $1.18 \%$ \\
\hline Citrate & 3 & 0.368 & [3] & 0.465 & $26.48 \%$ & 0.333 & $-9.51 \%$ \\
\hline Malate & 3 & 0.348 & [4] & 0.475 & $36.47 \%$ & 0.343 & $-1.33 \%$ \\
\hline Pyruvate & 3.33 & 0.377 & [4] & 0.531 & $40.83 \%$ & 0.384 & $1.82 \%$ \\
\hline Succinate & 3.5 & 0.385 & [1] & 0.507 & $31.60 \%$ & 0.350 & $-9.09 \%$ \\
\hline Gluconate & 3.67 & 0.535 & [4] & 0.621 & $16.01 \%$ & 0.449 & $-16.13 \%$ \\
\hline Acetate & 4 & 0.447 & {$[1,3]$} & 0.559 & $24.99 \%$ & 0.380 & $-15.08 \%$ \\
\hline Glucose & 4 & 0.535 & [4] & 0.739 & $38.20 \%$ & 0.535 & $-0.08 \%$ \\
\hline Fructose & 4 & 0.505 & {$[1]$} & 0.670 & $32.73 \%$ & 0.485 & $-4.03 \%$ \\
\hline Lactate & 4 & 0.510 & [4] & 0.642 & $25.87 \%$ & 0.464 & $-9.00 \%$ \\
\hline Formaldehyde & 4 & 0.470 & [4] & 0.701 & $49.25 \%$ & 0.507 & $7.91 \%$ \\
\hline Glycerol & 4.67 & 0.569 & {$[1]$} & 0.773 & $35.89 \%$ & 0.559 & $-1.75 \%$ \\
\hline Ethylenediamine & 5 & 0.660 & {$[2]$} & 0.823 & $24.77 \%$ & 0.595 & $-9.79 \%$ \\
\hline Methanol & 6 & 0.552 & [3] & 0.974 & $76.45 \%$ & 0.704 & $27.58 \%$ \\
\hline Ethanol & 6 & 0.558 & [1] & 0.899 & $61.15 \%$ & 0.632 & $13.25 \%$ \\
\hline $\begin{array}{l}95 \% \text { confidence level } \\
\text { of error }\end{array}$ & & & & & $47.9 \pm 0.12 \%$ & & $6.0 \pm 0.09 \%$ \\
\hline
\end{tabular}

( $Y_{\text {Exp }}$ refers to the experimental yield. Here, the average yield listed in the corresponding reference is considered as $Y_{\text {Exp }} ; Y_{\text {Est }}$ refers to the estimated yield by the original thermodynamic method; Error $=\frac{Y_{\text {est }}-Y_{\text {exp }}}{Y_{\text {exp }}}(\%)$; the energy utilizing coefficient was assumed as $K=0.6$ or $K=0.41$ for columns 5 and 7 respectively.) [1] Rutgers et al., 1989; [2] Yuan, 2004; [3] Heijnen and Roels, 1981; [4] Heijnen and vanDijken, 1992.

maintain this framework, the original model included some adjustments to deal with nitrogen sources other than ammonia. Since electron flow to oxygen as EA was already including, Reaction (1) below was proposed to account for electrons diverted from oxygen as EA to the nitrogen source.

$$
\frac{1}{20} \mathrm{NO}_{3}^{-}+\frac{1}{10} \mathrm{H}^{+}+\frac{1}{20} \mathrm{H}_{2} \mathrm{O}=\frac{1}{20} \mathrm{NH}_{4}^{+}+\frac{1}{10} \mathrm{O}_{2}
$$

Reaction (1) is energy consuming so the energy required for this reaction was added into the $\Delta G_{\mathrm{e}-\mathrm{s}}$ as $\Delta G_{\mathrm{n}}$. Later,

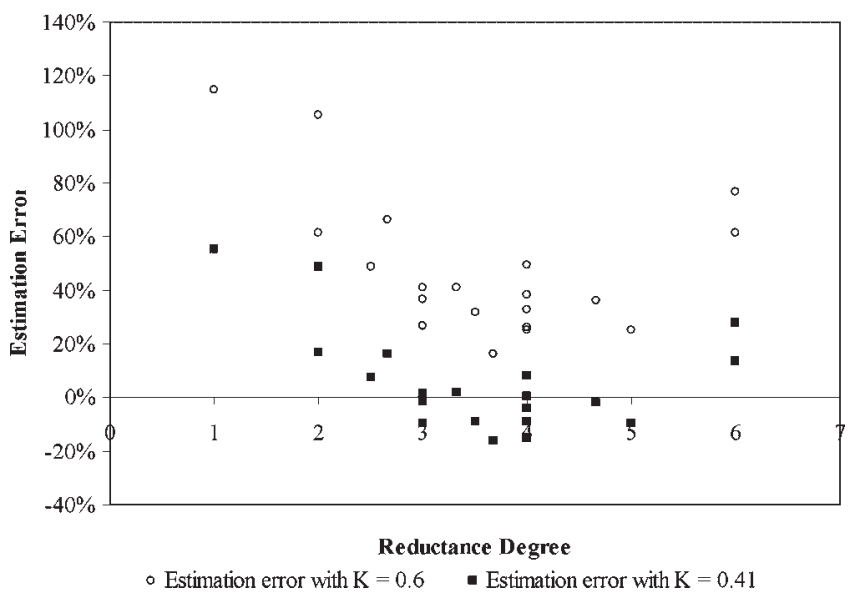

Figure 4. The relationship of the estimation error of the original model to the reductance degree of the carbon source substrate. The reductance degree of the carbon source is farther away from 4.2, the estimation error of the original model is bigger regardless $K$ is 0.6 (open circles) or 0.41 (solid squares).
Rittmann and McCarty (2001) deleted $\Delta G_{\mathrm{n}}$ from $\Delta G_{e-\mathrm{s}}$ and considered $\Delta G_{\text {c-cell }}$ to be different for different nitrogen sources. These methods are fundamentally equivalent and consistent in the calculation of electron balance. Unfortunately, in the calculation of energy balance, mixing the nitrogen flow and electron flow has similar problems as described above for carbon flow. $f_{s}^{0} \frac{\Delta G_{\mathrm{n}}}{K}$ is considered the total energy investment for NS reduction in the original model. However, the unit of $\Delta G_{\mathrm{n}}$ is kJ/e $\mathrm{e}^{-}$eq where the $\mathrm{e}^{-}$eq points to the electrons that flow to NS directly. But $f_{\mathrm{S}}^{0}$ is the electron fraction flowing into the carbon of CS that is incorporated into new biomass. For example, when $Y_{\mathrm{m}}$ mol-C new cell is formed, $f_{\mathrm{s}}^{0}=\frac{4.2 Y_{\mathrm{m}}}{Y_{\mathrm{s}}}$ fraction of electrons will flow into carbon of CS but only $\frac{\gamma_{\mathrm{s}}}{0.2 \times Y_{\mathrm{m}} \times\left(\gamma_{\left.\mathrm{N}-\mathrm{NH}_{3}-\gamma_{\mathrm{N}-\mathrm{NS}}\right)}\right.}$ fraction of electrons will flow into NS where $\gamma_{\mathrm{N}}$ is the reductance degree of nitrogen and 0.2 is the ratio of $\mathrm{N}$ and $\mathrm{C}$ in biomass based on the cell formula of $\mathrm{CH}_{2} \mathrm{O}_{0.6} \mathrm{~N}_{0.2}$. Clearly, direct coupling of electron flow, carbon flow and nitrogen flow is inappropriate. So it is necessary to treat the nitrogen source as a potential ED or EA independently. And when nitrogen plays several roles in the system, for example, $\mathrm{N}$ is electron donor and nitrogen source, a nitrogen balance is also needed. This will be discussed in the model formulation below.

\section{REFORMULATED THERMODYNAMIC TRUE YIELD PREDICTION MODEL}

The modifications to the original thermodynamic model suggested here are (1) the addition of carbon balance, (2) the addition of nitrogen balance, and (3) the reformulation of 
electron and energy balances to accommodate the coupled nature of the four critical balances in the system. Further, the important efficiency parameters of the model are re-set in terms of theoretical constructs and estimates of their values are presented.

\section{Carbon Balance}

The carbon balance is shown schematically in Figure 5. The amount of carbon in the carbon source should be equal to the sum of carbon in the end-products of carbon source utilization. There can be any number of carbon products in addition to the carbon used for synthesis. Acetate is used as the theoretical intermediate for synthesis instead of pyruvate in the original model since more yield data on acetate are available to estimate the energy utilization coefficient (see below). Moreover, the reductance degree of acetate, 4, is very near with that of cell, 4.2, while pyruvate has a reductance degree of 3.33. The carbon balance is expressed as (Eq. 2).

$$
f_{\mathrm{c}}+\sum_{i} f_{\mathrm{CS}}(i)=1
$$

Where, $f_{\mathrm{CS}}(i)$ is the fraction of carbon from the carbon source that is transformed into product, $i$, in C-mol product/ C-mol carbon source, and in order to keep consistent in symbols, here we use $f_{\mathrm{c}}$ to represent the fraction of carbon incorporated in new biomass, C-mol cell/C-mol carbon source, where $f_{\mathrm{c}}$ is equivalent to the maximum yield, $Y_{\mathrm{m}}$ in the unit of mol-C cell/mol-C CS.

\section{Nitrogen Balance}

The nitrogen balance (shown schematically in Fig. 6) is formulated such that the nitrogen in the original substrates equals the nitrogen found in all nitrogen-containing products. Often, the nitrogen balance does not affect yield prediction. For example, when bacteria use $\mathrm{NH}_{3}$ as nitrogen source, the nitrogen balance can be expressed as $\mathrm{N}$ in $\mathrm{NH}_{3}$, which is incorporated into cell equal to $\mathrm{N}$ in cell, which equals $0.2 \times Y_{\mathrm{m}} \mathrm{mol} \mathrm{N} / \mathrm{mol}-\mathrm{C}$ substrate for the assumed formula of cell biomass $\mathrm{CH}_{2} \mathrm{O}_{0.6} \mathrm{~N}_{0.2}$. Because the premise of this model is that energy (and not other growth elements such as N,P) is the limiting factor for bacterial growth, the existence of $\mathrm{NH}_{3}$ does not alter the carbon balance, electron flow or energy balance. Thus, when $\mathrm{NH}_{3}$ is the nitrogen source the nitrogen balance can be neglected in cell yield prediction and the nitrogen source merely used to formulate the overall stoichiometry following Rittmann and McCarty (2001). But when the complexity of the biological system increases, a nitrogen balance is critical. For example, when $\mathrm{NH}_{3}$ is used as electron donor as well as nitrogen source and it has several oxidized products (e.g., $\mathrm{NO}_{2}^{-}, \mathrm{NO}_{3}^{-}$), the nitrogen balance (shown in Eq. 3) must be considered.

$$
f_{\mathrm{N}-\mathrm{C}}+\sum_{i} f_{\mathrm{N}}(i)=1
$$

\section{Electron Balance}

The electron balance is shown schematically in Figure 7. After oxidation of the electron-donor substrate, the available electrons have been transferred to different products with different remaining reducing equivalents. We define $f_{\mathrm{ED}}(i)$ as the fraction of the electron donor that is oxidized into corresponding products $(i)$. The total available electrons that the electron donor can provide equals $\sum f_{\mathrm{ED}}(i) \times$ $\left(\gamma_{\mathrm{ED}}-\gamma(i)\right)$ where $\gamma_{\mathrm{ED}}$ and $\gamma(i)$ are the reductancie degrees of the electron donor and its oxidized product $(i)$. If there is more than one electron donor oxidized, the total available electrons are the sum of the electrons provided by each electron donor.

For the general case with potentially more than one electron acceptor, each $\mathrm{EA}(j)$, can be reduced by a different number of electrons $g(j)$. This number $g(j)$ is the number of the electron equivalents released from the electron donor that are sent to the electron acceptor, $j$. The total electrons that the electron donor(s) donate must be equal to the total electrons that the electron acceptor(s) accept. So the electron balance is

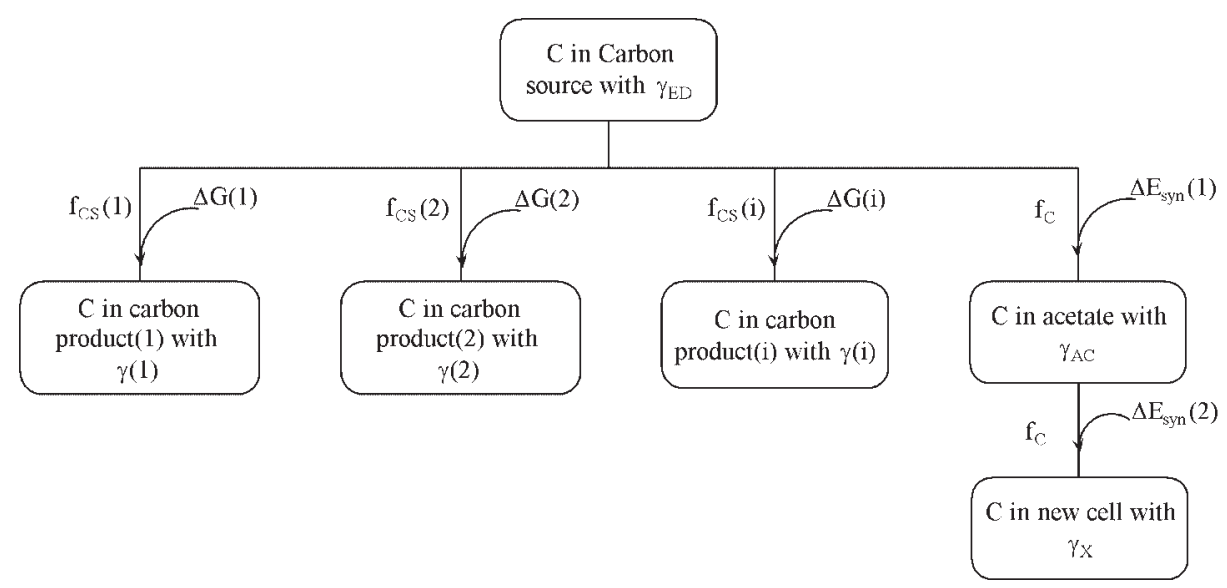

Figure 5. Schematic of proposed carbon balance for heterotrophs in the new model. $f_{\mathrm{CS}}(i)$ is the fraction of carbon flowing from carbon source to its product (i) and $\Delta G$ and $\Delta E_{\text {syn }}$ are the energy associated with the corresponding reaction. 


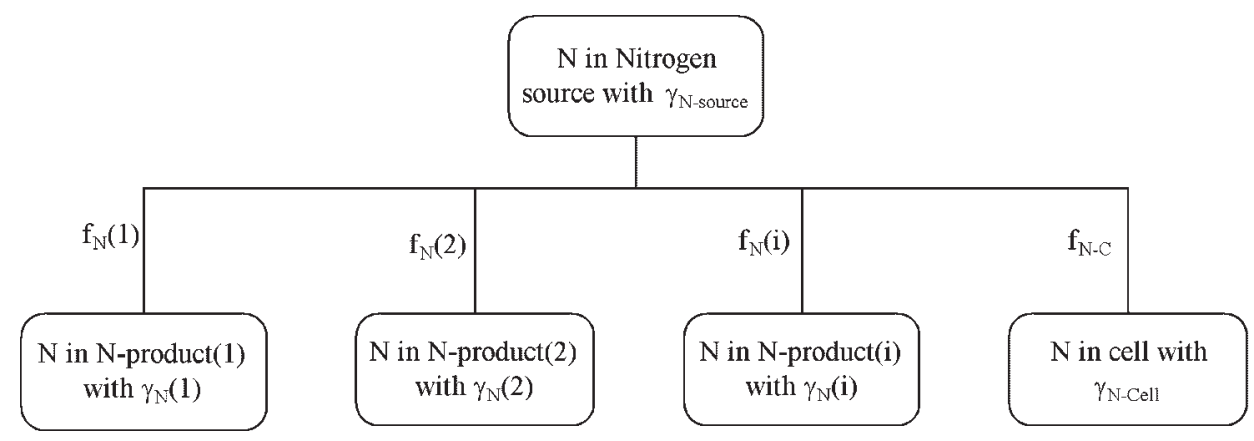

Figure 6. Schematic of proposed nitrogen balance in the new model.

expressed as (Eq. 4):

$$
\sum_{i} f_{\mathrm{ED}}(i) \times\left(\gamma_{\mathrm{ED}}-\gamma(i)\right)=\sum_{j} g(j)
$$

Where, $f_{\mathrm{ED}}(\mathrm{i})$ is the fraction of electron donor to the oxidized product $(i) ; \gamma_{\mathrm{s}}$ is the reductance degree of the electron donor; $\gamma(i)$ is the reductance degree of the oxidized product of the electron donor; and $g(j)$ is the number of electron equivalents released from electron donors and sent to the electron acceptor, $\mathrm{EA}(j)$ in unit of electron equivalent.

\section{Energy Balance}

Energy is always released or consumed with each step of catabolism and anabolism. For reactions releasing energy, part of the released energy is stored in ATP by the cell. The energy stored in this ATP is used for reactions requiring energy input. During energy utilization, the efficiency terms are introduced: the efficiency associated with capture of energy from the substrate and storage in ATP is defined as $K 1$;
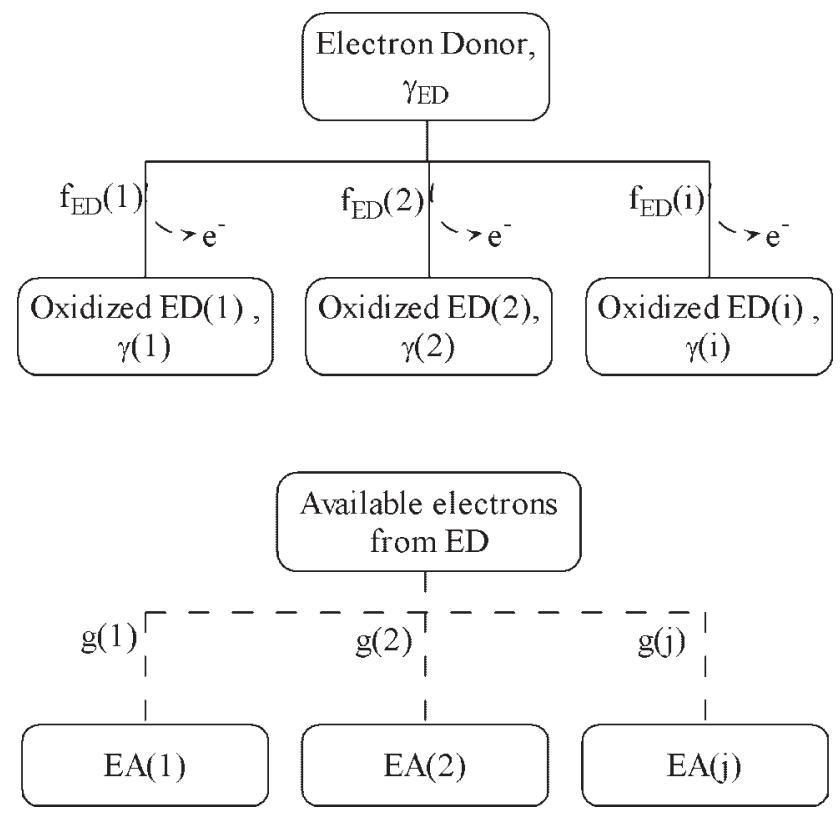

Figure 7. Schematic of proposed electron balance in the new model. the efficiency of energy transfer from ATP to cell synthesis reactions is defined as $K 2$. Both $K 1$ and $K 2$ are assumed to be constant for most organisms.

From the definition of $K 1$, the amount of ATP produced during catabolism is estimated as $\sum_{i} \frac{K 1 \times E_{\mathrm{p}}(i)}{\Delta G_{\mathrm{ATP}}}$ mol ATP, where $E_{\mathrm{p}}$ refers to the energy produced during step ( $i$ ) of substrate degradation that is available for ATP synthesis and $\Delta G_{\mathrm{ATP}}$ is the hydrolysis energy of ATP in unit of $\mathrm{kJ} / \mathrm{mol}$ ATP. From the definition of $K 2$, the total amount of ATP consumed by bacteria during anabolism is estimated as $\sum_{i=1}^{2} \frac{K(i) \times E_{\mathrm{syn}}(i)}{\Delta G_{\mathrm{ATP}}}$, where the value $E_{\text {syn }}(1)$, is equivalent to the energy needed from the reaction of carbon source to acetate, $\Delta G_{\mathrm{CS} \text {-acetate }}=$ $f_{\mathrm{c}} \times\left(\Delta G_{\mathrm{CS}}-\Delta G_{\text {acetate }}\right)$. Figure 5 (far right) shows these two energy values, and how they relate to the carbon balance. Here, $\Delta G_{\mathrm{CS}}$ is the Gibbs energy change from $\mathrm{CS}$ to $\mathrm{CO}_{2}$ in $\mathrm{kJ} /$ mol-C; the value $E_{\text {syn }}(2)$ is equivalent to $f_{\mathrm{c}} \Delta G_{\text {cell }}$, where $\Delta G_{\text {cell }}$ is the energy associated with formation of one mol-C of cells based on acetate and ammonia; And the efficiency, $K(i)$ is equal to $K 2^{-1}$ if $E_{\text {syn }}(i)$ is positive (energy consumed), otherwise, equal to $K 1$.

$\Delta G_{\text {cell }}$ cannot be calculated a priori from thermodynamics; however, several estimated values and estimation methods have been suggested (Baas-Becking and Parks, 1927; McCarty, 1965; Roels, 1980; Senez, 1962). Here, we follow the estimation method of McCarty (1965).

$$
\Delta G_{\text {cell }}=\frac{\Delta G_{\text {ATP }} \times M W_{\text {cell }}}{Y_{\text {ATP }} \times 0.9} \mathrm{~kJ} / \mathrm{mol}-\mathrm{C}
$$

Where, $\Delta G_{\mathrm{ATP}}$ is the energy released from ATP hydrolysis, $\Delta G_{\mathrm{ATP}}=30.53 \mathrm{~kJ} / \mathrm{mol}$ ATP (Burton, 1958); $M W_{\text {cell }}$ is the molecular weight of cell mass, $M W_{\text {cell }}=26.4 \mathrm{~g} / \mathrm{mol}-\mathrm{C}$ based on the formula of $\mathrm{CH}_{2} \mathrm{O}_{0.6} \mathrm{~N}_{0.2} ; Y_{\text {ATP }}$ is the bacteria yield per ATP, $Y_{\text {ATP }}=10.5 \mathrm{~g}$ dry weight $/ \mathrm{mol}$ ATP according to the experimental results of Bauchop (Bauchop, 1958; Bauchop and Elsden, 1960); and 0.9 is the assumed percentage of organic material in cell dry weight (Rittmann and McCarty, 2001).

With the above calculations completed, one final assumption is needed to create the energy balance. It is assumed that bacteria maximize their growth by optimizing the electron and carbon flow in the system to achieve the most energy production for cell synthesis. Thus, the ATP level in the cell is assumed to remain constant; all ATP synthesize from 
catabolism is used in anabolism. The energy balance can be expressed as:

$$
\begin{aligned}
\mathrm{ATP}_{\text {produced }}+\mathrm{ATP}_{\text {consumed }}= & 0 \rightarrow \sum_{i} \frac{K 1 \times E_{\mathrm{p}}(i)}{\Delta G_{\mathrm{ATP}}} \\
& +\sum_{i=1}^{2} \frac{K(i) \times E_{\mathrm{syn}}(i)}{\Delta G_{\mathrm{ATP}}}=0
\end{aligned}
$$

Given the definitions of $E_{\mathrm{p}}$ and $E_{\mathrm{syn}}$ discussed above, the energy balance is reformulated using notation consistent with the other balances as:

$$
K 1 \times \sum_{i} G(i)+\sum_{i=1}^{2} K(i) \times E_{\mathrm{syn}}(i)=0
$$

Where, $\Delta G(i)$ is the Gibbs energy change during the reaction $(i)$ shown in Figures 5-7 except the two steps of anabolism; $f_{\mathrm{c}}$ is the bacteria yield in C-mole cell/C-mole carbon source. $\Delta G(i)$ is calculated from standard half reactions. For example, when oxygen gains g(1) equivalent of electrons, the energy released should be equal to $g(1) \times$ $\Delta G_{\mathrm{eO}_{2}}$, where $\Delta G_{\mathrm{eO}_{2}}$ is the Gibbs energy change of $\frac{1}{4} \mathrm{O}_{2}+\mathrm{H}^{+}+\mathrm{e}^{-}=\frac{1}{2} \mathrm{H}_{2}$ Oin $\mathrm{kJ} / \mathrm{e}$-equivalent. And, when $f 1$ mol-C substrate goes into methane, the energy released is equal to $f 1 \times\left(\Delta G_{\text {substrate }}-\Delta G_{\text {methane }}\right)$, where $\Delta G$ is calculated based on the half reaction from organic compound to carbon dioxide in the unit of $\mathrm{kJ} / \mathrm{mol}-\mathrm{C}$. And in this paper, we standardize the proportions of $\mathrm{H}_{2} \mathrm{CO}_{3}, \mathrm{HCO}_{3}^{-}$, and $\mathrm{CO}_{3}^{2-}$ according to $\mathrm{pH}$ during writing the half reaction of organics' oxidation. See Equation (8) below.

$$
\begin{aligned}
& \frac{1}{a} \mathrm{C}_{a} \mathrm{H}_{b} \mathrm{O}_{c} \mathrm{~N}_{d}^{n+}+\frac{3 a-c}{a} \mathrm{H}_{2} \mathrm{O}=\alpha 1 \mathrm{H}_{2} \mathrm{CO}_{3} \\
& +\alpha 2 \mathrm{HCO}_{3}^{-}+\alpha 3 \mathrm{CO}_{3}^{2^{-}}+\frac{d}{a} \mathrm{NH}_{4}^{+} \\
& \quad+\left(6-2 \alpha 1-\alpha 2+\frac{b-2 c-4 d}{a}\right) \mathrm{H}^{+}+\gamma_{\mathrm{s}} \mathrm{e}^{-}
\end{aligned}
$$

(Note: $\alpha 1=1 /\left(\frac{k_{a 1} k_{a 2}}{[\mathrm{H}]^{2}}+\frac{k_{a 1}}{[\mathrm{H}]}+1\right), \alpha 2=1 /\left(\frac{k_{a 2}}{[\mathrm{H}]}+\frac{[\mathrm{H}]}{k_{a 1}}+1\right)$ and $\alpha 3=1-\alpha 1-\alpha 2$, where, $k_{a 1}$ and $k_{a 2}$ are the ionization constants of carbonic acid and reported as $10^{-6.35}$ and $10^{-10.33}$, respectively (Benjamin, 2002); [H] is the concentration of $\mathrm{H}^{+}$).

\section{RESULTS AND DISCUSSION}

\section{Estimation of Energy Capture Efficiency Terms}

In the original model, the energy capture efficiency coefficients were not estimated a priori based on their definitions but rather by comparing theoretical maximum yields computed at a specific standard state to observed experimental yields (McCarty, 1969). Obviously, problems with other model assumptions discussed above call into question the original estimation of $K$. Results presented by McCarty indicate $K$ in the range from 0.2 to 0.8 with the lower value associated with aerobic heterotrophs and higher value associated with anaerobic heterotrophs. Considering this wide range, assuming a constant value for $\mathrm{K}$ does not seem justified. Therefore, the energy capture coefficients are reestimated in the following according to their definitions without fitting experimental yield data directly.

$K 1$ is the energy-utilizing coefficient for bacteria capturing the energy released during substrate degradation and storing this energy in ATP. It is the percent of the energy released in the redox reaction between ED and EA that can be captured by cells and stored in ATP. Usually, the medial products of the substrates' degradation are transported into the citric acid cycle (TCA). During the TCA, the carbon chain is degraded and the electrons stored in it are released to electron carriers like $\mathrm{NAD}^{+}$and $\mathrm{FAD}^{+}$. The formed NADH or FADH continues to pass the electrons to other electron carriers and finally to the terminal EA. Therefore, it is sure all the energy released form the degradation of compounds in TCA cycle is available for forming ATP. To estimate $K 1$, the energy associated with transformations of compounds in the TCA cycle is used. See Table II. For compounds in the TCA cycle, the number of ATPs generated and the theoretical energy available through oxidation with oxygen as the terminal electron acceptor are known (Bender, 2002). And $K 1$ is calculated as the ratio of energy stored in ATP over the energy released from degradations. The mean of $\mathrm{K} 1$ is 0.393 and the $95 \%$ confidence interval is \pm 0.007 that is only $2 \%$ of 0.393. However, during fermentation, ATP is always formed through substrate level. For example, glucose is cleaved into two lactic acids through lactic fermentation. Where, $K 1$ is a little higher, around 0.5. But considering most ATP is produced through hydrogen gradient driven, not substrate level phyosphorylation, $K 1$ can be considered constant $(0.393)$ at least in aerobic system.

Assuming acetate as the starting media for cell synthesis, $K 2$ is defined as the energy utilizing coefficient of using ATP for synthesizing cells from acetate. Bacterial true yields on acetate have been widely reported; some are listed in Table III. Different species show slightly different yields. And 1 mole of acetate produces $11 \mathrm{~mol}$ ATP after complete oxidation (Bender, 2002), that is, $5.5 \mathrm{~mol}$ ATP is produced per $\mathrm{C}$-mole in acetate oxidation. So when 1 mol-C acetate is degraded as primary substrate, $1-Y_{\mathrm{m}}$ mol-C acetate is oxidized completely and $Y_{\mathrm{m}}$ mol-C is synthesized into new cell. During these processes, $5.5 \times\left(1-Y_{\mathrm{m}}\right)$ can be produced and only $K 2 \times 5.5 \times\left(1-Y_{\mathrm{m}}\right)$ mol ATP can be used for synthesizing new cell from acetate. Moreover, $\frac{Y_{\mathrm{m}} \times M W_{\text {cell }}}{Y_{\mathrm{ATP}} \times 0.9} \mathrm{~mol}$ ATP is needed for synthesizing $Y_{\mathrm{m}}$ mol-C new cell. So, $K 2$ can be computed by Equation (9). See Table III, $K 2$ is $0.414 \pm 0.064$ with $95 \%$ confidence level.

$$
K 2 \times\left(1-Y_{\mathrm{m}}\right) \times 5.5=\frac{Y_{\mathrm{m}} \times M W_{\text {cell }}}{Y_{\text {ATP }} \times 0.9}
$$

The estimations of $K 1$ and $K 2$ are very close in value so that the round average, $K=0.41$ will be used in the expanded 
Table II. Estimation of $\mathrm{K} 1$ (at $\mathrm{pH} 7)$.

\begin{tabular}{|c|c|c|c|c|c|c|c|}
\hline ED & $\gamma_{\mathrm{s}}$ & $\begin{array}{l}\text { Electron } \\
\text { acceptor }\end{array}$ & $\begin{array}{c}\Delta G_{\mathrm{ED}} \\
\left(\mathrm{kJ} / \mathrm{e}^{-} \mathrm{eq}\right)\end{array}$ & $\begin{array}{l}\text { Carbon } \\
\text { number }\end{array}$ & $\begin{array}{l}\text { Total energy released } \\
(\mathrm{kJ} / \mathrm{mol} \text { substrate })\end{array}$ & $\begin{array}{l}\text { ATP produced (unit/mol ED) } \\
\text { (Bender, 2002) }\end{array}$ & $K 1$ \\
\hline Glucose & 4 & $\mathrm{O}_{2}$ & -39.522 & 6 & -2837.82 & 36 & 0.389 \\
\hline Acetate & 4 & $\mathrm{O}_{2}$ & -26.576 & 2 & -842.36 & 11 & 0.400 \\
\hline Pyruvate & 3.33 & $\mathrm{O}_{2}$ & -33.850 & 3 & -1125.70 & 15 & 0.409 \\
\hline Citrate & 3 & $\mathrm{O}_{2}$ & -31.979 & 6 & -1992.58 & 26 & 0.400 \\
\hline Succinate & 3.5 & $\mathrm{O}_{2}$ & -28.416 & 4 & -1499.90 & 19 & 0.388 \\
\hline Ketoglutarate & 3.2 & $\mathrm{O}_{2}$ & -32.360 & 5 & -1777.28 & 23 & 0.397 \\
\hline Fructose & 4 & $\mathrm{O}_{2}$ & -39.599 & 6 & -2839.66 & 37 & 0.399 \\
\hline Malate & 3 & $\mathrm{O}_{2}$ & -33.056 & 4 & -1341.31 & 17 & 0.389 \\
\hline Oxalacetate & 2.5 & $\mathrm{O}_{2}$ & -36.474 & 4 & -1151.94 & 14 & 0.373 \\
\hline Fumarate & 3 & $\mathrm{O}_{2}$ & -33.345 & 4 & -1344.78 & 17 & 0.388 \\
\hline
\end{tabular}

(Note: Total released energy $=\left(-78.72+\Delta G_{\mathrm{e}-\mathrm{ED}}\right) \times \gamma_{\mathrm{s}} \times$ carbon number $\mathrm{kJ} / \mathrm{mol}-\mathrm{ED}$ where the value of -78.72 represents the energy released from the reduction half reaction of oxygen in $\mathrm{kJ} / \mathrm{e}^{-}$eq. Energy stored in ATP $=\Delta G_{\mathrm{ATP}} \times$ the amount of produced ATP kJ/mol-ED, where $\Delta G_{\text {ATP }}$ is energy released from ATP hydrolysis. $\Delta G_{\mathrm{ATP}}=-30.53 \mathrm{~kJ} / \mathrm{mol}$ ATP (Burton, 1958). $K 1=$ energy stored in ATP/total released energy. The mean of $K 1$ is 0.393 with standard error of 0.003 and its $95 \%$ confidence interval is \pm 0.007 ).

thermodynamic yield prediction model to represent both $K 1$ and $K 2$.

\section{Complete Model Prediction}

With the carbon balance, nitrogen balance, electron balance, and energy balance formulated, the system is fully specified. By solving the four equations simultaneously, the estimated true yield of bacteria, $f_{\mathrm{c}}$ (equivalent to $Y_{\mathrm{m}}$ in the original model) can be computed in carbon mole unit. These four equations are summarized in Table IV. With the energy capture coefficient estimated, the new expanded thermodynamic model can be applied. Given the variability in values of $K$ and the inherent variability of observed yields, we hypothesize the model will provide yield estimates with errors within $\pm 15 \%$. Here, a set of yields for aerobic bacteria are used as examples to demonstrate the new model and compare its results with the original model. Table $\mathrm{V}$ lists the reported and estimated yields on the substrates used in Table I. The average error of the new model for this data set is $+6.0 \%$. Figure 8 shows the direct comparison of the estimation errors for the original model. Although the average estimation error of the expanded model is almost the same as that of the original model with $\mathrm{K} 0.41$ for the data

Table III. The experimental yield of bacteria on acetate ( $\mathrm{pH}$ is assumed as 7).

\begin{tabular}{llc}
\hline $\begin{array}{l}\text { Reported maximum } \\
\text { yield, } Y_{\mathrm{m}} \text { (mol-C } \\
\text { cells/mol-C substrate) }\end{array}$ & Source citing primary source & $\begin{array}{c}\text { Calculated } \\
K 2\end{array}$ \\
\hline 0.406 & Heijnen and vanDijken, 1992 & 0.347 \\
0.455 & Heijnen and vanDijken, 1992 & 0.424 \\
0.410 & Linton and Stephenson, 1978 & 0.353 \\
0.471 & Sandler and Orbey, 1991 & 0.452 \\
0.5 & Heijnen and Roels, 1981 & 0.508 \\
0.44 & Heijnen and Roels, 1981 & 0.399 \\
\hline
\end{tabular}

(Mean of the yield on acetate is $0.447 \mathrm{~mol}-\mathrm{C}$ cell $/ \mathrm{mol}-\mathrm{C}$ acetate with standard deviation of 0.036 ; mean of $K 2$ is 0.414 with the standard deviation of 0.061 ). set presented, the regression line of the estimation error of the expanded model versus that of the original model has a slope of 0.66 which is less than 1 (shown as the reference line in Fig. 8). It represents estimation error associated with the new model are closer to 0 and its estimates are closer to the reported experimental yields than the original model.

The improvement is due to the incorporation of carbon balance only because the same $K$ value and the same Gibbs energy information are used for both models. In order to show the impact of carbon balance further, a one tail $t$-test was done on the absolute estimation errors associated with original model and expanded model. Because oxygenase reactions are common during the degradation of organic compounds with reductance degree higher than $\gamma_{X}$, the statistical analysis is only done on the substrates with $\gamma_{\mathrm{s}} \leq 4$. The data are summarized in Table VI. The null hypothesis, H0, is that the mean of absolute error of the expanded model $(\mu 1)$ is equal to that of the original model $(\mu 2)$. The alternative hypothesis is that $\mu 1<\mu 2$, which would imply the expanded model has improved prediction ability. The analysis $\left(t<-t_{\text {crit }}\right)$ rejects the null hypothesis with $95 \%$ confidence $(\alpha=0.05)$, and verifies the incorporation of carbon balance does improve the prediction ability. Moreover, we hypothesized that carbon is more unbalanced when $\gamma_{\mathrm{s}}$ is farther from $\gamma_{\mathrm{X}}$. The carbon difference can be calculated as $f_{\mathrm{s}}^{0} \times \frac{\gamma_{\mathrm{s}}-\gamma_{\mathrm{X}}}{\gamma_{\mathrm{X}}}$ based on comparing how carbon is determined in the original and expanded models. Figure 9 shows the relation between the carbon difference and the estimation error difference between the

Table IV. Four balances that summarize the expanded thermodynamic model for yield prediction.

\begin{tabular}{|c|c|}
\hline Balances & Equations \\
\hline Carbon balance & $f_{\mathrm{c}}+\sum_{i} f_{\mathrm{CS}}(i)=1$ \\
\hline Nitrogen balance & $f_{\mathrm{N}-\mathrm{C}}+\sum_{i} f_{\mathrm{N}}(i)=1$ \\
\hline Electron balance & $\sum_{i} f_{\mathrm{ED}}(i) \times\left(\gamma_{\mathrm{ED}}-\gamma(i)\right)=\sum_{j} g(j)$ \\
\hline Energy balance & $K 1 \times \sum_{i} G(i)+\sum_{i=1}^{2} K(i) \times E_{\mathrm{syn}}(i)=0$ \\
\hline
\end{tabular}


Table V. Estimated yields using the expanded model ( $\mathrm{pH} 7)$.

\begin{tabular}{|c|c|c|c|c|c|}
\hline Electron donor and C-source & $\gamma_{\mathrm{s}}$ & $\begin{array}{c}Y_{\text {experimental }} \\
(\mathrm{mol}-\mathrm{C} \text { cell/mol-C ED) }\end{array}$ & Reference & $\begin{array}{c}Y_{\text {estimated }} \\
(\mathrm{mol}-\mathrm{C} \text { cell/mol-C ED) }\end{array}$ & Error \\
\hline Oxalate & 1 & 0.086 & [4] & 0.107 & $24.82 \%$ \\
\hline Formate & 2 & 0.162 & {$[4]$} & 0.216 & $33.50 \%$ \\
\hline Glyoxylate & 2 & 0.220 & {$[1]$} & 0.247 & $12.38 \%$ \\
\hline Tartrate & 2.5 & 0.280 & [1] & 0.297 & $6.23 \%$ \\
\hline Malonate & 2.667 & 0.238 & [1] & 0.268 & $12.54 \%$ \\
\hline Iminodiacetate (IDA) & 3 & 0.333 & {$[2]$} & 0.337 & $1.09 \%$ \\
\hline Citrate & 3 & 0.368 & [3] & 0.334 & $-9.37 \%$ \\
\hline Malate & 3 & 0.348 & [4] & 0.342 & $-1.65 \%$ \\
\hline Pyruvate & 3.33 & 0.377 & [4] & 0.397 & $5.39 \%$ \\
\hline Succinate & 3.5 & 0.385 & [1] & 0.383 & $-0.45 \%$ \\
\hline Gluconate & 3.67 & 0.535 & [4] & 0.464 & $-13.35 \%$ \\
\hline Acetate & 4 & 0.447 & {$[1,3]$} & 0.446 & $-0.24 \%$ \\
\hline Glucose & 4 & 0.535 & {$[4]$} & 0.501 & $-6.39 \%$ \\
\hline Fructose & 4 & 0.505 & [1] & 0.501 & $-0.77 \%$ \\
\hline Lactate & 4 & 0.510 & [4] & 0.480 & $-5.90 \%$ \\
\hline Formaldehyde & 4 & 0.470 & [4] & 0.524 & $11.58 \%$ \\
\hline Glycerol & 4.667 & 0.596 & {$[1,4]$} & 0.578 & $1.59 \%$ \\
\hline Ethylenediamine (ED) & 5 & 0.660 & {$[2]$} & 0.616 & $-6.72 \%$ \\
\hline Methanol & 6 & 0.552 & [3] & 0.728 & $31.92 \%$ \\
\hline Ethanol & 6 & 0.558 & [1] & 0.692 & $24.01 \%$ \\
\hline Average Error & & & & & $6.0 \pm 0.06 \%$ \\
\hline
\end{tabular}

(All the experiments were done with ammonia as nitrogen source at neutral $\mathrm{pH}$. And assume there is no oxygenase reaction involving in the degradation pathways of those substrates). [1] Rutgers et al., 1989; [2] Yuan, 2004; [3] Heijnen and Roels, 1981; [4] Heijnen and vanDijken, 1992.

expanded model and the original model. The biggest differences between errors are sent where the carbon differences are highest for the models (lower left of Fig. 9). The strong correlation between the carbon difference and estimation error difference supports the need to add a fully coupled carbon balance to the original model formulation.

\section{CONCLUSIONS}

Thermodynamic methods to predict true yield and stoichiometry of bacterial reactions allow prediction in the absence of detailed pathway information. Previous models have showed good predictive ability for many compounds, but have failed

Table VI. Comparison of absolute estimated errors of original and expanded model ( $\mathrm{pH} 7)$.

\begin{tabular}{|c|c|c|c|c|c|}
\hline ED \& CS & $\gamma_{\mathrm{s}}$ & Abs(Error 1) & Abs(Error 2) & $\begin{array}{c}\text { Carbon } \\
\text { difference }\end{array}$ & $\begin{array}{c}\text { Error } \\
\text { difference }\end{array}$ \\
\hline Oxalate & 1 & $24.82 \%$ & $55.27 \%$ & $-42.73 \%$ & $-30.45 \%$ \\
\hline Formate & 2 & $33.50 \%$ & $48.55 \%$ & $-26.47 \%$ & $-15.05 \%$ \\
\hline Glyoxylate & 2 & $12.38 \%$ & $16.43 \%$ & $-28.18 \%$ & $-4.05 \%$ \\
\hline Tartrate & 2.5 & $6.23 \%$ & $7.57 \%$ & $-20.48 \%$ & $-1.34 \%$ \\
\hline Malonate & 2.67 & $12.54 \%$ & $16.19 \%$ & $-15.86 \%$ & $-3.65 \%$ \\
\hline Iminodiacetate & 3 & $1.09 \%$ & $1.18 \%$ & $-13.48 \%$ & $-0.09 \%$ \\
\hline Citrate & 3 & $9.37 \%$ & $9.51 \%$ & $-13.32 \%$ & $0.13 \%$ \\
\hline Malate & 3 & $1.65 \%$ & $1.33 \%$ & $-13.74 \%$ & $-0.32 \%$ \\
\hline Pyruvate & 3.33 & $5.39 \%$ & $1.82 \%$ & $-10.03 \%$ & $3.57 \%$ \\
\hline Succinate & 3.5 & $0.45 \%$ & $9.09 \%$ & $-7.00 \%$ & $8.64 \%$ \\
\hline Gluconate & 3.67 & $13.35 \%$ & $16.13 \%$ & $-6.48 \%$ & $2.77 \%$ \\
\hline Acetate & 4 & $0.24 \%$ & $15.08 \%$ & $-1.90 \%$ & $14.84 \%$ \\
\hline Glucose & 4 & $6.39 \%$ & $0.08 \%$ & $-2.67 \%$ & $-6.31 \%$ \\
\hline Fructose & 4 & $0.77 \%$ & $4.03 \%$ & $-2.42 \%$ & $3.26 \%$ \\
\hline Lactate & 4 & $5.90 \%$ & $9.00 \%$ & $-2.32 \%$ & $3.09 \%$ \\
\hline Formaldehyde & 4 & $11.58 \%$ & $7.91 \%$ & $-2.54 \%$ & $3.67 \%$ \\
\hline Average abs(Error) & & $9.10 \%$ & $13.70 \%$ & & \\
\hline
\end{tabular}

(Error 1: the estimation error of new model with $K=0.41$; Error 2: the estimation error of original model with $K=0.41$; Abs(error): the absolute value of estimation error which represents the distance to horizontal line $($ error $=0)$; One tail $t$-test is done with the original hypothesis H0: mean of abs(Error 1$)=$ mean of abs(Error2) and alternative hypothesis, H1: mean of abs(Error 1) $<$ mean of abs(Error 2). And with 95\% confidence $(\alpha=0.05$ ), $t_{\text {crit }}=1.75$ and $t=-2.02 . t<-t_{\text {crit }}$, the original hypothesis is rejected. Where, carbon difference is the estimated carbon difference based on the original model and equal to $f_{\mathrm{s}}^{0} \times \frac{\gamma_{\mathrm{s}}-\gamma_{\mathrm{x}}}{\gamma_{\mathrm{x}}}$; Error difference is the difference between estimation error of expanded model and original model and equal to Error1 - Error2). 

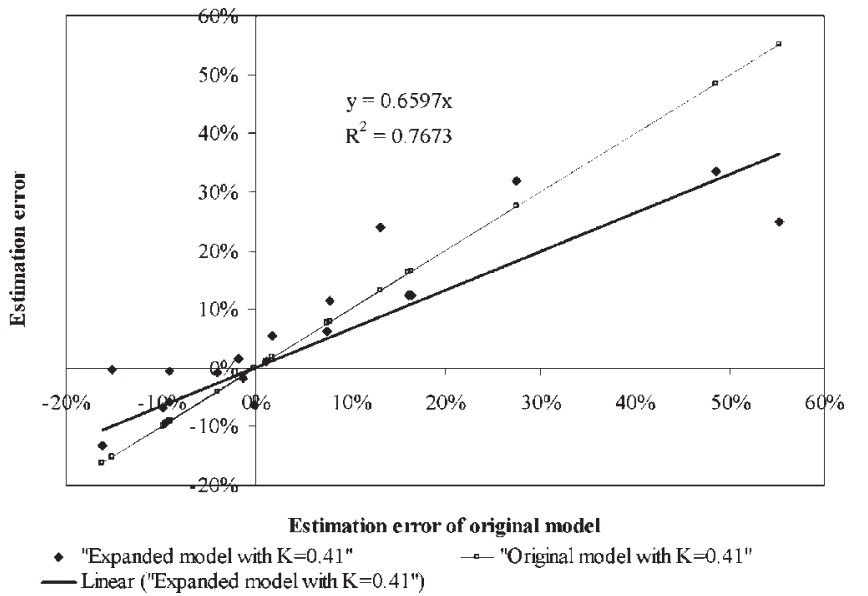

Figure 8. Comparison of the estimation error by the original model and the expanded model with the same $K$ value of 0.41 . The estimation errors of the original model (open squares) are used for reference providing a regression line with the slope of 1 . The solid diamonds represent the estimation errors of the expanded model. And the linear regression of the estimation error of the expanded model $(y)$ and that of the original model $(x)$ is $y=0.6597 x$ with $R$ square of 0.7673 .

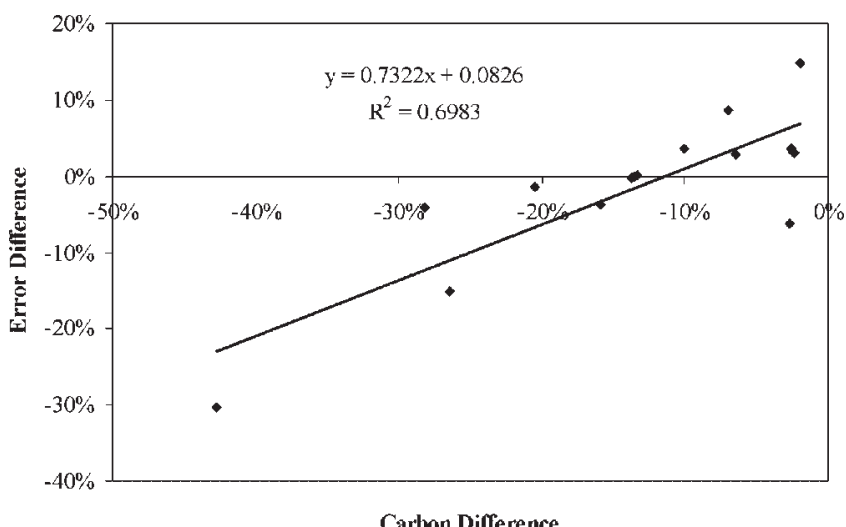

Figure 9. Comparison of the carbon difference and the estimated difference in yield prediction for the original and new model.

to predict accurately the yields of some common easily degraded substrates with well known yield values. In this work we identify a limitation in the thermodynamic yield prediction method related to the assumption of carbon oxidation state. When carbon, not energy or reducing equivalents, constrains growth a more complete model incorporating a fully coupled carbon balance along with electron and energy balances is needed. Use of this model is particularly important when the carbon source compound has a degree of reductance far from that of the cell biomass to be formed. Under these circumstances this expanded thermodynamic model shows improved predictive ability.

\section{LIST OF SYMBOLS}

$\begin{array}{ll}\text { ED } & \text { electron donor } \\ \text { EA } & \text { electron acceptor }\end{array}$

ATP adenosine triphosphate

ADP adenosine diphosphate

$\mathrm{C}$

$\mathrm{N}$

$\mathrm{P}$

$\mathrm{Pi}$

$\gamma_{\mathrm{s}}$

$\gamma_{\mathrm{X}}$

$\gamma_{\mathrm{ED}}$

$\gamma(i)$

$\gamma_{\text {acetate }}$ or $\gamma_{\mathrm{AC}}$

$Y$

$Y_{\mathrm{m}}$

$f_{\mathrm{s}}$
$f_{\mathrm{e}}$
$K$

carbon

nitrogen

phosphorus

inorganic phosphate

the reductance degree of substrate

the reductance degree of cell carbon

the reductance degree of electron donor

the reductance degree of the oxidized product $(i)$ of electron donor

the reductance degree of acetate

bacterial yield in the unit of mol-C cell per mol-C substrate the maximum bacterial yield in the unite of mol-C cell per mol-C substrate

the fraction of electrons to cell synthesis

the fraction of electrons to energy generation

the energy-utilizing coefficient in the original model

$\Delta G_{\mathrm{e}-\mathrm{R}} \quad$ the energy released from redox reaction between ED and

EA per electron (kJ/e ${ }^{-}$eq.)

$\Delta G_{\mathrm{e}-\mathrm{ED}} \quad$ the energy released form oxidation reaction of ED per electron (kJ/e ${ }^{-}$eq.)

$\Delta G_{\mathrm{e}-\mathrm{EA}} \quad$ the energy released form reduction reaction of EA per

$\Delta G_{\mathrm{e}-\mathrm{s}} \quad$ the energy needed for cell synthesis ( $\mathrm{kJ} / \mathrm{e}^{-}$eq.)

$\Delta G_{\mathrm{p}} \quad$ the energy needed from carbon source to pyruvate $\left(\mathrm{kJ} / \mathrm{e}^{-}\right.$eq. $)$

$\Delta G_{\mathrm{n}} \quad$ the energy needed for nitrogen source (kJ/ $\mathrm{e}^{-}$eq.)

$\Delta G(i) \quad$ the Gibbs energy released from the degradation of certain compound $(\mathrm{kJ} / \mathrm{mol}-\mathrm{C})$

$\Delta G_{\text {cell }} \quad$ the energy needed from media to new biomass (kJ / mol-C biomass)

the energy released from ATP hydrolysis ( $\mathrm{kJ} / \mathrm{mol}$ ATP)

the overall reaction

the half reaction reaction of cell synthesis

the half reaction of electron acceptor

the half reaction of electron donor

the distribution coefficient of $\mathrm{H}_{2} \mathrm{CO}_{3}$ in aquatic system the distribution coefficient of $\mathrm{HCO}_{3}^{-}$in aquatic system the distribution coefficient of $\mathrm{CO}_{3}^{2-}$ in aquatic system the concentration of hydrogen ion

the ionization constants of carbonic acid

the fraction of carbon from the carbon source that is transformed into product (i)

is the fraction of carbon incorporated in new biomass

$f_{\mathrm{c}}$

$f_{\mathrm{ED}}(i)$

$g(j)$

$E_{\mathrm{p}}$

\section{$E_{\text {syn }}$}

ATP $_{\text {produced }}$

$\mathrm{ATP}_{\text {consumed }}$

$M W_{\text {cell }}$

$Y_{\text {ATP }}$

$K 1$ the fraction of electron donor to its oxidized product (i) the electrons that electron acceptor, $\operatorname{EA}(j)$ gains $\left(\mathrm{e}^{-}\right.$eq.) the produced energy during substrate degradation that is available to ATP formation $(\mathrm{kJ})$

the energy needed to synthesize $\mathrm{Y}_{\mathrm{m}}$ mol-C cell mass $(\mathrm{kJ})$ ATP produced from substrate degradation (mol ATP)

ATP consumed for cell synthesis (mol ATP)

the molecular weight of cell mass ( $\mathrm{g} / \mathrm{mol}-\mathrm{C}$ cell) bacterial yield per mol ATP ( $\mathrm{g}$ dry weight/mol ATP) the energy-utilizing coefficient of released energy from redox reaction to form ATP

$K 2$
The authors acknowledge the active exchange of comments and ideas with Dr. Perry McCarty, Stanford University, and Dr. Bruce Rittmann, Arizona State University, during revision of this manuscript.

\section{References}

Alvarez PJJ, Anid PJ, Vogel TM. 1994. Kinetics of toluene degradation by denitrifying aquifer microorganism. J Environ Eng 120(5):1327-1337. 
Arcangeli JP, Arvin E. 1999. Modeling the growth of a methanotrophic biofilm: Estimation of parameters and variability. Biodegradation 10: $177-191$.

Baas-Becking LGM, Parks GS. 1927. Energy relations in the metabolism of autotrophic Bacteria. Physiol Revs 7:85-106.

Bauchop T. 1958. Observations on some molar growth yields of bacteria and yeasts. J General Microbiol 18:vii.

Bauchop T, Elsden SR. 1960. The growth of microoganisms in relation to their energy supply. J General Microbiol 23:457-469.

Beller HR, Spormann AM, Sharma PK, Cole JR, Reinhard M. 1996. Isolation and characterization of a novel toluene-degrading, sulfate-reducing bacterium. Appl Environ Microbiol 62(4):1188-1196.

Bender DA. 2002. Introduction to nutrition and metabolism. London: Taylor $\&$ Francis Inc.

Benjamin MM. 2002. Water chemistry. New York: McGraw-Hill Companies, Inc.

Burland S, Edwards EA. 1999. Anaerobic benzene biodegradation linked to nitrate reduction. Appl Environ Microbiol 65(2):529-533.

Burton K. 1958. Energy of adenoising triphosphate. Nature 181:15941595.

Corseuil HX, Weber WJ. 1994. Potential biomass limitations on rates of degradation of monoaromatic hydrocarbons by indigenous microbes in subsurface soils. Water Res 28(6):1415-1423.

Edwards EA, Grbic-Galic D. 1994. Anaerobic degradation of toluene and o-xylene by a methanogenic consortium. Appl Environ Microbiol 60(1):313-322.

Hayes AM, Flora JRV, Khan J. 1998. Research note: Electrolytic stimulation of denitrificaiton in sand columns. Water Res 32(9):2830-2834.

Heijnen JJ, Roels JA. 1981. A macroscopic model describing yield and maintenance relationships in aerobic fermentation processes. Biotechnol Bioeng 23:739-763.

Heijnen JJ, vanDijken JP. 1992. In search of a thermodynamic description of biomass yields for the chemotrophic growth of microorganisms. Biotechnol Bioeng 39:833-858.

Heijnen JJ, vanLoosdrecht MCM, Tijhuis L. 1992. A black box mathematical model to calculate auto- and heterotrophic biomass yields based on Gibbs energy dissipation. Biotechnol Bioeng 40:1139-1154.

Hooker BS, Skeen RS, Petersen JR. 1994. Biological destruction of $\mathrm{CCl}_{4}$ : II kinetic modeling. Biotechnol Bioeng 44:211-218.

Linton JD, Stephenson RJ. 1978. A preliminary study on growth yields in relation to the carbon and energy content of various organic growth substrates. FEMS Microbiol Lett 3:95-98.

McCarty PL, Thermodynamics of biological synthesis and growth. In: Baers $\mathrm{J}$, editor. Advances in water pollution research: Proceedings of the 2nd International Conference on Water Pollution Research. Oxford, England: Pergamon Press, Inc. pp 169-199.

McCarty PL. 1969. Energetics and bacterial growth. The Fifth Rudolf Research Conference. The State University, New Bruswick, NJ: Rutgers.

McCarty PL. 1971. Energetics and bacterial growth. In: Faust SD, Hunter JV, editors. Organic compounds in aquatic environments. New York: Marcel Dekker, Inc.
McCarty PL. 1972a. Energetics of organic matter degradation. In: Mitchell R, editor. Water pollution microbiology. New York: Wiley-Interscience.

McCarty PL. 1972b. Stoichiometry of biological reactions. Paper presented at the International Conference toward a Unified Concept of Biological Waste Treatment Design.

McCarty PL. 1975. Stoichiometry of biological reactions. Progress in Water Technology 7:157-172.

Muller A, Wentzel MC, Loewenthal RE, Ekama GA. 2003. Heterotroph anoxic yield in anoxic aerobic activated sludge systems treating municipal wastewater. Water Res 37(10):2435-2441.

Noguera DR, Brusseau GA, Rittmann BE, Stahl DA. 1988. A unified model describing the role of hydrogen in the growth of Desulfovibrio vulgaris under different environmental conditions. Biotechnol Bioeng 59:732746.

Nowak O, Franz A, Svardal K, Muller V, Kuhn V. 1999. Parameter estimation for activated sludge models with the help of mass balances. Water Sci Technol 39(4):113-120.

Rittmann BE, McCarty PL. 2001. Environmental biotechnology: Principles and applications. New York: McGraw-Hill Book Company.

Roels JA. 1980. Application of macroscopic principles to microbial metabolism. Biotechnol Bioeng 22:2457-2514.

Roels JA. 1983. Energetics and kinetics in biotechnology. Amsterdam: Elsevier.

Rutgers M, vanderGulden HML, vanDam K. 1989. Thermodynamic efficiency of bacterial growth calculated from growth yield of Pseudomonas oxalaticus OX1 in the chemostat. Biochim Biophys Acta 973:302307.

Sandler SI, Orbey H. 1991. On the thermodynamics of microbial growth processes. Biotechnol Bioeng 38:697-718.

Schill N, Liu JS, vonStockar U. 1999. Thermodynamic analysis of growth of Methanobacterium thermoautotrophicum. Biotechnol Bioeng 64: 74-81.

Senez JC. 1962. Some considerations on the energetics of bacterial growth. Bacteriological Reviews 26:95-107.

VanBriesen JM. 2001. Thermodynamic yield predictions for biodegradation through oxygenase activation reactions. Biodegradation 12(4):265281.

VanBriesen JM. 2002. Evaluation of yield predictions using thermodynamics. Biodegradation 13:171-190.

VanBriesen JM, Rittmann BE. 2000. Mathematical description of microbiological reactions involving intermediates. Biotechnol Bioeng 67(1): 35-52.

Woo SH, Rittmann BE. 2000. Microbial energetics and stoichiometry for biodegradation of aromatic compounds involving oxygenation reactions. Biodegradation 11(4):213-227.

Yuan Z. 2004. The role of oxygenation and intermediates in biodegradation of chelating agents. Carnegie Mellon University.

Yuan Z, VanBriesen JM. 2002. Yield prediction and stoichiometry of multistep biodegradation reactions involving oxygenation. Biotechnol Bioeng 80:100-113.

Zitomer DH. 1998. Stoichiometry of combined aerobic and methanogenic COD transformation. Water Res 32(3):669-676. 